\title{
The Correlation of Low-Velocity Impact Resistance of Graphite-Fiber-Reinforced Composites With Matrix Properties
}

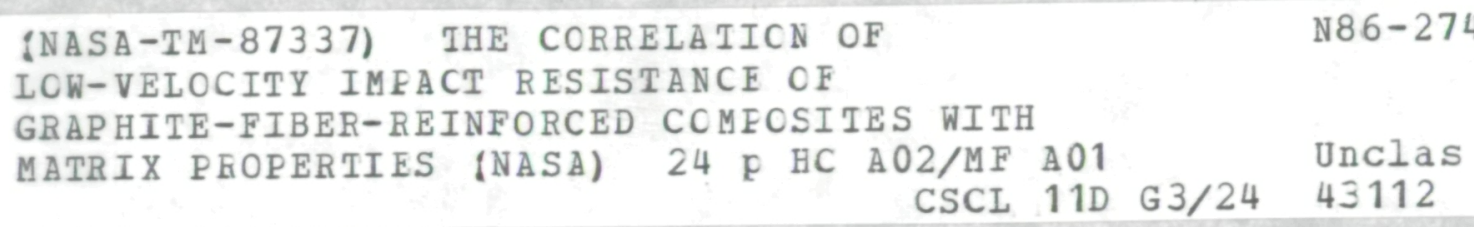

Kenneth J. Bowles

Lewis Research Center

Cleveland, Ohio

Prepared for

Composite Materials Testing and Design: Eighth Symposium sponsored by the American Society for Testing and Materials Charleston, South Carolina, April 29-May 1, 1986

\section{NRSA}


THE CORRELATION OF LOW-VELOCITY IMPACT RESISTANCE OF GRAPHITE-FIBER-

\author{
REINFORCED COMPOSITES WITH MATRIX PROPERTIES \\ Kenneth J. Bowles \\ National Aeronautics. and Space Administration \\ Lewis Research Center \\ Cleveland, Ohio 44135
}

\begin{abstract}
SUMMARY
This paper summarizes basic studies that were conducted to correlate the impact resistance of graphite-fiber-reinforced composites with polymer matrix properties. Three crosslinked epoxy resins and a linear polysulfone were selected as composite matrices. As a group, these resins possess a significantly large range of mechanical properties. The mechanical properties of the resins and their respective composites were measured. Neat resin specimens and unidirectional and crossply composite specimens were impact tested with an instrumented drop-weight tester. Impact resistances of the specimens were assessed on the basis of loading capability, energy absorption, and extent of damage :
\end{abstract}

\title{
INTRODUCTION
}

The emphasis for the development of tougher graphite fiber reinforced composites has brought about a significant increase in composite impact testing and composite toughness evaluation. One means of assessing the low-velocity impact resistance of composites, which has received an unusually large amount of attention, is that of using an instrumented drop-weight impact tester. This tester generates load and energy data as a function of both time after contact and laminate deflection during an impact test. These data can be used to provide valuable information about the impact failure mechanisms and the variables which significantiy affect the impact resistance of graphitefiber-reinforced polymer matrix composites. A guide for acquiring acceptable data from this type of equipment and the subsequent evaluation of the data has been presented in reference. 1 .

When the drop-weight impact. tester is used to evaluate the impact resistance of a composite material, it is very important that one understands the process which is taking place during the impact event and the subsequent failure. Also, one must know the extent of the influence of the specimen size and design on the resulting data. The word, design, is used to denote the sequence of ply orientation as one traverses through the thickness of the composite specimen. If these effects are well understood, then one can more confidently evaluate the effect of the selected variables on the impact resistance of composites.

The study reported herein was conducted to determine the effects of specimen thickness, ply layup, fiber content, and matrix properties on the low-velocity impact resistance of graphite-fiber-reinforced polymer matrix composites, through the understanding of the mechanisms involved in the deformation and fallure processes during impact. 
Three epoxy resins and a polysulfone resin were used as matrices for the composites studied. These resins were selected because their mechanical properties and behavior differ quite significantly from resin to resin. Significant ranges in moduli, tensile strengths, and strain at fallure were attained with the selection of these resins:

The properties of these resins and their respective composites were characterized by the use of a number of mechanical and physical test methods. Resin and composite toughness was evaluated by using fracture toughness measurement techniques and low-velocity, instrumented, drop-weight impact tests.

The results of this study indicate that the mechanical properties of the matrix resin do have an effect on the impact resistance of crossplied graphitefiber-reinforced composites. Of equal importance, they also indicate that the selection of specimen size and ply layup strongly influence the reaction of the composite laminate to low-velocity impact and thus the interpretation of test data can be misleading if these effects are not considered. The consideration of these effects can be used to design effective testing programs.

\section{MATERIALS}

The graphite fiber which was used for the composite reinforcement in this study was Celion 6000. Unsized fiber was selected for use so that the sizing materials would not have to be included as a possible source of influence on the results of the study. Four resins were studied as composite matrices. The first of these was a strongly cross linked aromatic diglicidyl ether of bisphenol A (DGEBA). The resin was the fiberite 930 resin, and the curing agent, which was premixed with the resin, was an aromatic diamine. This resin has a relatively high strength at fallure, a high tensile modulus, and a relatively low strain at fallure.

The second resin which was selected was the Union Carbide P-1700 polysulfone, a tough, thermally stable thermoplastic resin. This resin has a tensile strength almost as great as that of the 930 resin, yet its strain at yeild, which is defined herein as the strain at maximum stress, where the slope of the stress-strain curve is zero, is over twice as great as that of the 930 resin. The tensile modulus is about half that of the highly crossinked epoxy resin.

The last two resins that were chosen for study were flexibilized resins that were formulated from two Ciba-Geigy resins. One of the formulated resins was mixed as follows:

$$
\begin{array}{ll}
\text { Ciba-Geigy } 6010 \text { Resin } & 50 \mathrm{~g} \\
\text { Ciba-Geigy } 508 \text { Resin } & 50 \mathrm{~g} \\
\text { Ciba-Geigy } 840 \text { Hardener } & 24.5 \mathrm{~g}
\end{array}
$$

This mixture will hereafter be referred to by the hardener designation ( 840 resin). The other is:

$$
\begin{array}{ll}
\text { Ciba-Geigy } 6010 \text { Resin } & 40 \mathrm{~g} \\
\text { Ciba-Geigy } 508 \text { Resin } & 60 \mathrm{~g} \\
\text { Ciba-Geigy } 956 \text { Hardener } & 17.5 \mathrm{~g}
\end{array}
$$

This resin will be designated by the hardener identification also (956 resin). 
The 6010 resin is a diglicidyl ether of bisphenol A (DGEBA). The 508 resin is a modified 6010 resin. The 6010 resin is diluted with an epoxidized polyol; the proportions are unknown. The polyol becomes a flexibilizer, connecting the 6010 chain units. Because of the introduction of the polyol into the chain structure, the average distance between crosslinks increases. Also, the long polyol segments can fold and intertangle which results in an increase in the free volume of the formulated resin over that of the 6010 resin. Because of the decrease in crosslink density and the more flexible backbone structure, these two resins possess low tensile strengths, low tensile moduli, and relatively high strains to yield. Also, they have low glass transition temperatures $\left(T_{g}{ }^{\prime} s\right)$.

The 956 hardener is an oxylated triethylene tetramine (TETA). The 840 hardener is a polyamide.

\section{COMPOSITE FABRICATION}

All composites were made up from unidirectional prepreg plies. Laminate fabrication was accomplished by using the following general procedure:

(1) Fiber winding -5.1 turns/cm (13 turns/in.)

(2) Impregnation

(a) 930 - solvent solution (72 percent solids)

(b) 840 and 956 - solventless

(c) P-1700 - wet winding technique (10 percent solids)

(3) All composite laminates were made by compression molding in matched metal die molds. Compression pressures were provided by heated hydraulic presses. The laminate processing parameters are described elsewhere (ref. 2) along with the details of the entire fabrication procedures.

(4) The molds and laminates were removed from the press, allowed to cool in air, and then the cured laminates were removed from the mold. The epoxy laminates were post cured at their respective cure temperature for an hour.

Laminate quality was determined by two methods. Through transmission, ultrasonic C-scans were run on each laminate after fabrication and then, when possible, samples were cut from the laminates and examined microscopically for voids and cracks.

\section{TESTING PROCEDURE}

Tests were conducted to characterize both the bulk resins and their respective composites. For resins, these tests were the following:

(1) Tensile test

(2) Compression test

(3) Dynamic moduli measurement

(4) Thermal mechanical analys is

(5) Density measurement

(6) Fracture toughness measurement

(7) Impact test 
For composites, the tests were the following:

(1) Tensile test

(2) Compression test

(3) $10^{\circ}$ off-axis intralaminar shear test

(4) Three point bend test

(5) Double cantilever beam fracture toughness test

(6) Dynamic moduli measurement

(7) Thermal mechanical analys is

(8) Impact test

The details of the test procedures are given elsewhere (ref. 2).

Many tests have traditionally been used to assess impact resistance of materials including the simple and inexpensive Charpy. Izod, and falling dart tests. The Charpy and Izod tests are constrained significantly by sample geometry and dimensions. The results available from these tests are not really applicable as models for end-use conditions, because there are significant edge effects (ref. 3) and geometry effects (ref. 4) which are not usually present in real structural components.

Both the neat resins and the composites prepared from them were impact tested with an instrumented falling-weight impact tester. Automatic electronic data analysis in the Dynatup system provides graphical and tabular records of applied load, as measured by a strain-gauged tup, and energy absorbed as a function of either time or specimen deflection during impact. Impact performance can be evaluated in terms of all of the characteristics of the fracture process. For example, total absorbed energy is simply segmented into that required for initiating failure and that for propagating the failure. The drop-weight impact test requires the use of a relatively large sample, but past experience seems to indicate that it produces more realistic impact mode1ing than either the Izod or Charpy tests.

The impact test machine is shown in figure 1(a). It is composed of a weighted crosshead containing a $1.27-\mathrm{cm}-(0.50-$ in.-) diameter cylindrical penetrator with a spherical end. Figure 1(b) shows the details of the penetrator configuration and the mode of interaction with the sample. By varying the height, from which the crosshead is dropped, and weight of the crosshead, a wide range of impacting energies and impacting speeds can be produced with this machine. Typical load-deflection and energy-deflection curves for each type of crossplied composite studied are shown in figure 2. The rest of the system functions are described in reference 1 .

Both the neat resin samples and the composite samples measured $15.2 \mathrm{~cm}$ ( 6 in.) by $15.2 \mathrm{~cm}$ ( $6 \mathrm{in.}$ ). The thickness varied from about $0.127 \mathrm{~cm}$ $(0.050 \mathrm{in.})$ to $0.500 \mathrm{~cm}(0.200 \mathrm{in.})$. Four types of composite samples were tested. These types were as follows:

(1) Fifteen plies in a balanced $0^{\circ} / 90^{\circ}$ fiber orientation sequence

(2) Thirty plies in a balanced $0^{\circ} / 90^{\circ}$ fiber orientation sequence

(3) Eight plies in a balanced $0^{\circ} / 90^{\circ}$ fiber orientation sequence

(4) Fifteen plies in a unidirectional stacking sequence

The samples were clamped along all four edges during the tests. 


\section{RESULTS AND DISCUSSION}

\section{Neat Resins Materials}

The results of the resin-fracture toughness tests are given in table I. The resin drop weight impact test data are tabulated in table il.

If one compares the tensile data, fracture toughness data, and the impact. data for the four resins, it is apparent that there are differences in the toughness rankings of the resins depending. on which test results one uses to rank the resins: Figure 3 shows the tensile stress-strain curves for the four matrix resins. If the polymer toughness is assessed on the bas is of the area under the stress-strain curves, the ranking would be as follows:

$$
956>840>P-1700>930
$$

When the evaluation of toughness is based on the energy absorbed up to the maximum load point where the slope of the stress-strain curve is zero for the four resins the following ranking results:

$$
P-1700>930>956>840
$$

In either case, these rankings do not agree with those from the results of the fracture toughness or impact test data. The impact test rankings are the same whether one bases the ranking on load at failure or energy absorbed by the specimen at fallure. The ranking is

$$
\text { P-1700>956>840>930 }
$$

The toughness ranking of the matrix resins, as measured by the compact tensile specimen fracture toughness test, depends on whether one uses $K_{I C}$ or ${ }$ IC as the basis for ranking. Of the four methods illustrated above for assessing the toughness of homogeneous materials, no two methods give identical rankings. These data 111 ustrate need for a proper understanding of the materials properties which are paramount in influencing the test data. Also, it is necessary that a proper definition of the "toughness" parameter be estabiished so that a relevant test method may be used to measure that parameter. We will now look at the instrumented falling-weight impact test to see what material or specimen properties are of importance in assessing matrix resin impact resistance.

In correlating the toughness of the impacted plates with resin mechanical. properties, one can observe a relationship between the maximum impact load and the resin strain. Where the load drops to zero or where the load first: ceases. to increase with increasing strain. This is shown in figure 4 . The results of this study also indicate a relationship between the maximum load and also the energy absorbed up to fallure with the fraction of the load carried by membrane action of the resin plate (figs. 5 and 6). The fraction: of the load carried by membrane action $K$. under static loading was calculated from an expression presented by Sturm and Moore. (ref. 5) which is

$$
K=i-\frac{1}{1+0.12 y^{2 / t^{2}}}
$$

where $y$ is the deflection of the plate and $t$ is the plate thickness. 
As the plate deflects more than one-half of its thickness, the in-plane stresses in the plate start increasing, due to the stretching of the plate out of the original plane of the unstressed plate, and they continue to increase as the deflection increases. It may be construed then, that the greater the strain to failure a material exhibits, the greater amount of out-of-plane deflection that a plate made from that material will undergo before failure occurs. As a result of this, the amount of membrane action which develops within the plate will be greater. This indicates an apparent toughness which is greater for the resins with larger strain to failure when subjected to dropweight impact testing. Therefore the drop-weight impact test, when it is used to evaluate the toughness, of the types of resins studied, actually measures the amount of in-plane stresses that can be generated within that material before failure. It is obvious that maximum loads and energies of impact are dependent on the material modulus. The effect of tensile strength is not as obvious as the dependence on the strain at fatlure or yield. This is apparent when tensile strengths and moduli are plotted against energy and load as was done with strains in figure 4.

\section{Unidirectional Composite Impact Resistance}

When a unidirectional composite is impacted, one may imagine that the impact load is borne almost totally by the strip of fibers in contact with the impactor. Some of the load is naturaliy transferred by the matrix to neighboring fibers, but because of the fact that the transverse moduli of unidirectional composites are so much less than the longitudinal moduli, one would expect that most of the strain energy is absorbed by the fibers in direct contact with the impactor.

The load and energy data from the impact tests were normalized to 60 vol \% of fiber by using the rule of mixtures from the relationship

$$
P_{n}, E_{n}=\left(0.6 / K_{v f}\right) P_{a}, E_{a}
$$

Here $P$ is the load, $E$ is the energy, and the subscripts $n$ and a denote normalized and actual, respectively. These normalized load and energy data are presented in table III. Basically, the composites failed in two different ways. The first fallure mode was that of the cracking and punching out of a central, longitudinal strip of fibers with a definite width - punch out failure. The second mode of fallure was that of the propagation and opening up of a central crack in the composite and the subsequent wedging of the impactor through the crack-splitting fallure. Both types of fallure are shown in fig-. ure 7. In the latter mode of fallure, no fiber breakage occurred, except for compressive fiber and/or shear fracture on the impacted surface fibers of the specimens. For composites of approximately the same thickness, the composites with the stronger matrices exhibited the punch out damage, and the weaker matrix composites exhibited splitting damage. When the thicknesses of the latter composites were increased, punch out damage occurred during impact. It appears that the amount of composite deflection that occurs during the test, and the matrix strength control the type of damage which occurs in unidirectional composites during drop-weight impact testing. The splitting type of fallure seems to occur with the thinner composites which sustain greater 
deflections during impact. This could be caused by the development of significant transverse in-plane stresses large enough to cause interfiber matrix cracking to occur before fiber fracture occurs.

When the load at fallure values are normalized to 60 vol $\%$ of fiber, they correlate linearly very well with thickness, as is shown in figure 8 . If one treats the central strip as a beam clamped at both ends, the stress at the surface of the beam, Sc, can be computed as shown below

$$
S c=\frac{3 P L}{4 b t^{2}}
$$

where

$L \quad$ span of the beam

P load

b width of the beam

$t$ thickness of the beam

Upon rearranging, the load exhibits the following relationship with thickness

$$
P=\frac{S c b t^{2}}{L}
$$

If one substitutes $S_{f} K_{v f}$ for $S_{C}$, where $S_{f}$ is the tensile strength of the fiber, then the load is a function of $k_{v f} b t^{2}$. When actual loads at.failure are plotted against $K_{v f} b t^{2}$ there is considerable scatter and the trend suggests that the above relationship in equation (4) does not hold. Two nonlinear regression analyses were performed to fit the data to exponential relationships with (1) thickness and (2) the $K_{v f} b^{2}$ term. The results of the first analysis is shown as a curve in figure 7. The value of the exponent of thickness is 1.25 and not 2 . Two points are to be made from figure 8 . One is that the amount of data scatter is relatively low. The second point is that there appears to be no difference in the load-thickness relationships for either type of failure. In contrast, when the relationship resulting from equation (4) is plotted, the scatter in the data increases so much that it is impossible to calculate a representative equation for the data. The data displayed in this figure suggests that the impact failure of these types of specimens is not really related to flexural fallure.

The energy of penetration, which is a part of the difference between the total energy $Q_{t}$ and the energy at maximum load $Q_{m}$, is the energy required to break through the composite after fallure initiates. The energy of penetration appears to correlate somewhat with the composite thickness, but scatter in the data hides any possibly significant relationship.

\section{Crossply Composites}

Table IV presents the data from the impact tests of crossplied composites. The data have been normalized to 60 vol $\%$ of fiber using the standard rule of mixtures relationship. One can see from the data that there appears to be a relationship between the damage criteria (damage area, energy, and loading) and composite thickness. 
When the normalized loads at initiation of damage are plotted against composite thicknesses, as in figure 8 , it is apparent that there is a different linear relationship between the load and thickness for each of the four types of crossplied composites studied. Three points of importance are to be noted from this figure. The differences between the loading, sustained for the different composites (with different matrices), increases as the composite thickness increases. The linear relationship for all of the different types of composites appear to converge at a thickness of about $0.05 \mathrm{in} .(0.13 \mathrm{~cm})$. The load at initiation of failure of the P-1700 composites appears to be independent of specimen thickness. It was found that the actual loads at initiation of damage do exhibit a linear relationship with thickness. The data scatter for the $P-1700$ is significant.

The load-bearing capability of the composites with the epoxy matrices can be related to the shear strength of the composites. This is illustrated in figure 9 where measured shear strengths are plotted against the normalized load at the initiation of damage for the three different specimen thicknesses. All the curves look as if they converge at a shear strength of about $35 \mathrm{MN} / \mathrm{m}^{2}$ ( $5 \mathrm{ksi}$ ). The data point for the P-1700 composites is shown on the figure. It appears that when the shear strength approaches the value of $35 \mathrm{MN} / \mathrm{m}^{2}$ ( $5 \mathrm{ksi}$ ), the thickness of the composite does not affect normalized load at failure. The convergence could possibly indicate a change in the mode of failure at the point of convergence. The new failure mode, which could be interlaminar shear, does not exhibit a sensitivity to the law of mixtures method for normalizing load data. Figure 10 shows the relationship between the maximum load sustained and the composite thickness. The loads have been normalized to 60 vol \% of fiber. A curve, calculated by nonlinear regression analysis, has been drawn for each type of crossplied composite that was studied. Except for the P-1700 composites, all the data appear to lie very close together, and they could all possibly be represented by a single curve. A statistical t-test indicates that no differences exist between the data for the different composites with the crosslinked matrices. All of the epoxy composites show a dependence of the normalized load on the thickness to a power of about 1.0 to 1.2 . The exponential value for the $P-1700$ composite data is about 0.75 . When all the data for the epoxy composites are fitted to an exponential curve, the calculated thickness exponent is 1.2 with a standard deviation of 0.08 . The $r^{2}$ value is 93 percent. From these data it appears that the maximum load shows no significant dependence on epoxy-matrix mechanical properties as did the load at initiation of fallure. This response is similar to the response of the unidirectional specimens. The different relationship shown for the thermoplastic P-1700 matrix composites is probably due to a different failure mechanism.

Figure 11 shows a relationship between composite shear moduius and the extent of internal damage caused by an impact. One can see that the extent of damage decreases as the composite shear modulus increases. As the composite shear modulus increases past $4.2 \mathrm{G} \mathrm{N} / \mathrm{m}^{2}(600 \mathrm{ksi})$, the effectiveness in reducing the damage area decreases, since the curve appears to asymptotically approach the cross-sectional area of the penetrator itself. The slope of the curve can be represented by the following equation:

$$
\text { Percent of damage }=2.27 \times 10^{4} \mathrm{G}^{-3 / 2}
$$

These data are from the impact tests conducted with the thirty-ply composites. As the thickness of the laminate decreases, the differences in the extent of 
internal damage from impact also decreases for the four composites that were tested. The damage energies of the 956,840 , and $P-1700$ composites, normalized to 60 vol \% of fiber, do increase with increasing thickness, but, as with the energy data from the unidirectional tests, the data are scattered so that no significantly defined relationship can be observed. The penetration energy is the energy absorbed after damage and before final fallure at the maximum load. For 930 composites, this value was zero for all thicknesses less than $0.442 \mathrm{~cm}(0.175 \mathrm{in.})$. The energy value is a measure of the amount of internal damage caused by the impact and penetration. When one compares energy data from table IV with fracture toughness data presented in table $I$, it is evident that there is no correlation of crossplied composite impact resistance with resin-fracture toughness.

\section{DAMAGE MECHANISMS}

All the epoxy-matrix crossply composites appear to fall by the same mechanism. Figure 12(a) shows the impacted surface of the 956 composite specimen. Note the pair of lines, perpendicular to each other, that extend out from the impact site. These radiating lines extend to the limits of the initernal damage area. Microphotograhs of these fallure lines are shown in figure 12(b). The appearance of the fallures suggest a shear-type compressive failure has occurred. From the results of this study, it is unclear as to what type of plate reaction caused the fallure to occur. It was previously noted that the relationship between the normalized load and specimen thickness was linear for both the load at initiation of fallure and the maximum load. If the fallure was related to a beam fallure, the load would be related to the thickness. squared. If the fallure was due to the flexure of a square plate, clamped at the edges, the load would increase as the cube of the plate thickness (ref. 5). This suggests a shear-controlled fallure mechanism. It appears that the composite impact resistance is generally influenced by both resin-matrix strength and modulus as suggested in reference 6 .

Figure 13(a) shows the fracture surface of a $10^{\circ}$ of $f$-axis 930 composite, tensile test specimen. Note the matrix debris that is present on the surface of the fibers. This indicates a strong matrix-fiber bond. In contrast, figure $13(\mathrm{~b})$ shows the fracture surface of a $10^{\circ}$ off-axis $P-1700$ tensile test specimen that was tested to fallure. The bare surfaces of the fiber suggest that there was little if any interfacial bonding between the P-1700 matrix and the graphite fiber. Ten degree off-axis tensile tests were conducted on the P-1700 composites and the measured intralaminar shear strength was the lowest of the four composites. The modulus was greater than that of the two composites with the flexibllized matrices. Figure 14 shows the impactdamaged cross section area of the P-1700 composite specimen. Note the presence of a single separation that is located approximately in the center of the laminate thickness. All other types of crossplied composites that were impac - ted contained damaged areas with multiple separations through the thickness. The evidence observed in figures 12 and 13 suggest that the initial.fallure of the P-1700 impact specimens was due to interlaminar shear fallure caused by a lack of adequate interfacial bonding between the P-1700 matrix and the graphite fiber. 

follows:

The significant results of this investigation can be summarized as

1. Matrix strength and moduli are more important than matrix failurestrain capability in predicting and assessing crossplied graphite-fiberreinforced composite impact resistance.

2. Unidirectional composite impact resistance and crossplied composite maximum loading are not significantly dependent on matrix properties.

3. The composite impact resistances are related to specimen thickness in a nearly linear relationship when the impact data are normalized to a common fiber-volume fraction by the standard rule of mixtures. The linear relationship suggests a predominant shear-induced fallure mode.

4. The contribution of the composite shear properties on the crossplied composite impact resistance increases as the specimen thickness increases.

5. Impact induces two types of failure modes for crosspiled composites: (a) Shear-induced compression fallure on the impacted surface.

(b) Interlaminar shear fallure.

6. The ranking of the neat resin impact specimens, in terms of load sustained during impact, is in the reverse order of that of the crossplied composites that had these resins as their matrices.

7. A direct relationship between resin impact toughness and graphitefiber-reinforced composite impact resistance was not established by using the drop-weight impact test to measure impact toughness.

\section{REFERENCES}

1. Cheresh, M.C., McMichae1, S., "Instrumented Impact Test Data Interpretation," Presented at the ASTM Symposium on Instrumented Impact Testing of Plastics and Composite Materials, March 11-12, 1985, Houston, Texas. (to be published)

2. Bowles, K.J., "Fundamental Studies of Low Velocity Impact Resistance of Graphite Fiber Reinforced Polymer Matrix Composites;"Ph. D. Thesis, Case Western Reserve University, Cleveland, Ohio, 1985.

3. Pipes, R.B., Kaminski, B.E. and Pagano, N.J., in Analysis of the Test Methods for High Modulus Fibers and Composites, ASTM STP-521, ASTM, Philadelphia, 1973, pp. 218-229.

4. Adams, D.F., in Composite Materials: Testing and Design, ASTM STP-617, ASTM, Philadelphia, 1977, pp. 409-426.

5. Sturm, R.G. and Moore, R.L., Journal of Applied Mechanics, Vol. 4, No. 2, June 1937, pp. A75-A85.

6. Chamis, C.C. and Smith, G.T., AIAA Journal, Vol. 23, No. 6, June 1985, pp. $902-911$. 
TABLE I. - COMPACT TENSILE SPECIMEN FRACTURE TOUGHNESS FOR MATRIX RESINS

\begin{tabular}{|c|c|c|c|}
\hline Resin & $\begin{array}{l}\text { Thickness, } \\
\text { cm (in.) }\end{array}$ & $\mathrm{N} / \mathrm{cm}^{-1.5} \stackrel{\mathrm{K}_{\mathrm{IC}},}{(\mathrm{lb} / \mathrm{in} .-1.5)}$ & $\mathrm{J} / \mathrm{cm}^{2}{ }^{\mathrm{G}}\left(\mathrm{in},-1 \mathrm{~b} / \mathrm{in} .{ }^{2}\right)$ \\
\hline $\begin{array}{r}930 \\
930 \\
930 \\
P-1700 \\
P-7700 \\
P-1700 \\
840 \\
840 \\
840 \\
956 \\
956 \\
956\end{array}$ & $\begin{array}{r}0.640(0.250) \\
.640(.250) \\
.640(.250) \\
.640(.250) \\
.640(.250) \\
.640(.250) \\
1.207(.475) \\
1.207(.475) \\
1.207(.475) \\
1.460(.750) \\
1.460(.750) \\
1.460(.750)\end{array}$ & $\begin{array}{l}2010(1839) \\
2160(1965) \\
2143(1950) \\
4175(3799) \\
4179(3802) \\
4199(3821) \\
1895(1725) \\
1917(1744) \\
1905(1733) \\
3511(3295) \\
3544(3225) \\
3536(3218)\end{array}$ & $\begin{array}{l}0.04(2.50) \\
.05(2.63) \\
.05(2.88) \\
.36(20.65) \\
.36(20.65) \\
.36(20.65) \\
.12(6.61) \\
.12(6.61) \\
.12(6.68) \\
.56(31.90) \\
.57(32.50) \\
.56(31.90)\end{array}$ \\
\hline
\end{tabular}

TABLE II. - RESIN IMPACT TEST DATA

\begin{tabular}{|r|c|c|c|c|c|}
\hline Resin & $\begin{array}{c}\text { Maximum } \\
\text { load, } \\
\text { N (1b) }\end{array}$ & $\begin{array}{c}\text { Maximum } \\
\text { energy, } \\
\text { (ft-lb) }\end{array}$ & $\begin{array}{c}\text { Load carried by } \\
\text { membrane action, } \\
\text { percent }\end{array}$ & $\begin{array}{c}\text { Thickness, } \\
\text { cm (in.) }\end{array}$ & $\begin{array}{c}\text { Maximum } \\
\text { deflection, } \\
\text { cm (in.) }\end{array}$ \\
\hline 930 & $667(150)$ & $1.4(1.0)$ & 15.8 & $0.284(0.112)$ & $0.346(0.140)$ \\
$P-1700$ & $3336(750)$ & $20.3(15.0)$ & 77.2 & $.300(.118)$ & $1.778(.700)$ \\
840 & $823(185)$ & $3.0(2.2)$ & 38.7 & $.342(.134)$ & $.782(.308)$ \\
956 & $1970(443)$ & $8.8(6.5)$ & 53.6 & $.330(.130)$ & $1.016(.400)$ \\
\hline
\end{tabular}


TABLE III. - UNIDIRECTIONAL COMPOSITE IMPACT TEST DATA NORMALIZED TO 60 Vol \% FIBER

\begin{tabular}{|c|c|c|c|c|c|c|}
\hline Matrix & $\begin{array}{c}\text { Thickness, } \\
\mathrm{cm} \text { (in.) }\end{array}$ & $K_{v f}$ & ${ }_{N}^{P_{1}}(i b)$ & $\mathrm{N}_{\mathrm{m}}^{\mathrm{P}}(\mathrm{ib})$ & $\begin{array}{c}Q_{j} \\
J(f t-l b)\end{array}$ & $\mathrm{J}(\mathrm{qm}, \mathbf{f t}-1 \mathrm{~b})$ \\
\hline $\begin{array}{r}930 \\
930 \\
P-1700 \\
P-1700 \\
P-1700 \\
840 \\
840 \\
a 840 \\
a 840 \\
956 \\
956 \\
\text { ag56 } \\
\text { ag56 }\end{array}$ & 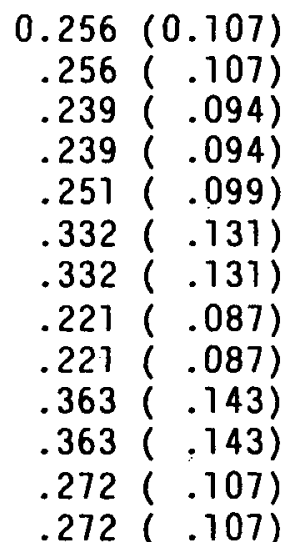 & $\begin{array}{l}0.520 \\
.520 \\
.598 \\
.598 \\
.580 \\
.420 \\
.420 \\
.638 \\
.638 \\
.390 \\
.390 \\
.548 \\
.548\end{array}$ & $\begin{array}{l}3921(882) \\
2910(654) \\
2673(601) \\
2009(452) \\
2429(543) \\
4257(957) \\
4003(900) \\
1535(345) \\
2326(523) \\
5477(1237) \\
4729(1063) \\
2669(600) \\
2922(657)\end{array}$ & $\begin{array}{ll}3921 & (882) \\
3080 & (692) \\
2673 & (601) \\
2285 & (514) \\
2494 & (561) \\
4257(957) \\
4003(900) \\
1640(369) \\
2548(573) \\
5477(1237) \\
4729(1063) \\
2708(609) \\
2976(669)\end{array}$ & $\begin{aligned} & 13.6(10.2) \\
& 11.8(8.7) \\
& 11.9(8.8) \\
& 6.8(5.0) \\
& 9.5(7.0) \\
& 15.1(11.7) \\
& 15.1(11.7) \\
& 6.4(4.7) \\
& 11.0(8.1) \\
& 20.9(15.4) \\
& 18.9(14.0) \\
& 10.1(7.4) \\
& 11.2(8.2)\end{aligned}$ & $\begin{aligned} & 13.6(10.2) \\
& 11.8(8.7) \\
& 11.9(8.8) \\
& 6.8(5.0) \\
& 9.5(7.0) \\
& 15.1(11.1) \\
& 15.9(11.7) \\
& 8.6(6.3) \\
& 16.0(11.8) \\
& 20.9(15.4) \\
& 18.9(14.0) \\
& 15.0(10.9) \\
& 18.5(13.7)\end{aligned}$ \\
\hline
\end{tabular}

awedging faflure. 
TABLE IV. - CROSSPLIED COMPOSITE IMPACT TEST DATA NORMALIZED TO 60 Vol \% FIBER

\begin{tabular}{|c|c|c|c|c|c|c|}
\hline Matrix & $\begin{array}{l}\text { Thickness, } \\
\mathrm{cm} \text { (in.) }\end{array}$ & $K_{v f}$ & ${ }_{N}^{P_{j}}(i b)$ & ${ }_{N}^{P_{m}}$ & $\begin{array}{c}Q_{j} \\
J(f t-1 b)\end{array}$ & $J \stackrel{Q_{m},}{(f t-1 b)}$ \\
\hline 9 & f & & 7 & 6 & & 4.8 \\
\hline & & & $9 i$ & 2 & $6.7 \%$ & 32.5 \\
\hline & 9 & & & & 12.7 & 12.4 \\
\hline & $.099)$ & & $4 i 1$ & 41 & 12.819 & 12.6 \\
\hline 9 & 7 & & $8(1$ & 8 & $16.1 \%$ & $15.9 \%$ \\
\hline 930 & & .4 & $6(1$ & $6 i$ & $17.6 \%$ & $17.6 i$ \\
\hline & 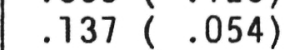 & & & & 5.7 & 5.71 \\
\hline 9 & & & & & $5.3 \%$ & 5.3 \\
\hline 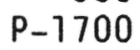 & & & & 0 & 0.8 ( & 14.2 \\
\hline & & & $4(7$ & 21 & $4.8(3$ & $16.9 \%$ \\
\hline & 7 & & $2(6$ & 25 & $7.4(5$ & $7.4 i$ \\
\hline & & & 816 & $4 i$ & $11.3<8$ & 11.2 ( \\
\hline & 0 & & $9(6$ & 4 ( & $6.2) 4$ & $9.4 i$ \\
\hline & 1 & & $0(5$ & 4 & $6.2(4$ & 8.9 \\
\hline & 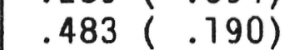 & & $2(1$ & 91 & $10.7<7$ & 22.61 \\
\hline & ) &.$t$ & $8(1$ & 2( & $12.0(8$ & 40.6 \\
\hline 8 & ) & .7 & $9(6$ & 81 & $8.1(6$ & 17.7 \\
\hline & ) & . & $4(\epsilon$ & 3732 & $8.8(6$ & $14.8 i$ \\
\hline & .10 & .6 & 3020 & 3105 & $4.7(3$ & 9.91 \\
\hline & $.070)$ & .5 & $2962(6$ & 2962 i6 & $8.6(6.4)$ & $8.6 i c$ \\
\hline & $.070)$ & .5 & 2891 (6 & 2891 & $8.9(6$ & $8.9 i$ \\
\hline & $.176)$ & .6 & 3416 & 7566 & $3.9 i$ & $35.8 \%$ \\
\hline & $.774)$ & & 4074 & 8149 (1 & $8.8 i$ & $37.1(27.5)$ \\
\hline & $.099)$ & .6 & 3438 (7 & 4087 & $7.3<5$ & $16.2(12.0)$ \\
\hline & .08 & .6 & 3193 (7 & 4452 & $8.9) 6$ & $20.1(74.9)$ \\
\hline & $.363(.143)$ & .4 & 3180 & 7655 (1 & $26.2(19.4)$ & $35.8(26.5)$ \\
\hline & $.750)$ & .4 & 2936 & 7343 (1 & $13.0(9.6)$ & $18.8(13.9)$ \\
\hline & $.178 ; .07$ & .6 & $2682(6$ & $2682 / 6$ & $6.4 i 4$ & $6.4(4.8)$ \\
\hline & $.178(.070)$ & .650 & $2771) 6$ & 2771 & $6.1) 4$ & $6.1(4.5)$ \\
\hline
\end{tabular}




\section{ORIGNAL PAGE. IS \\ OF POOR QUALTY}

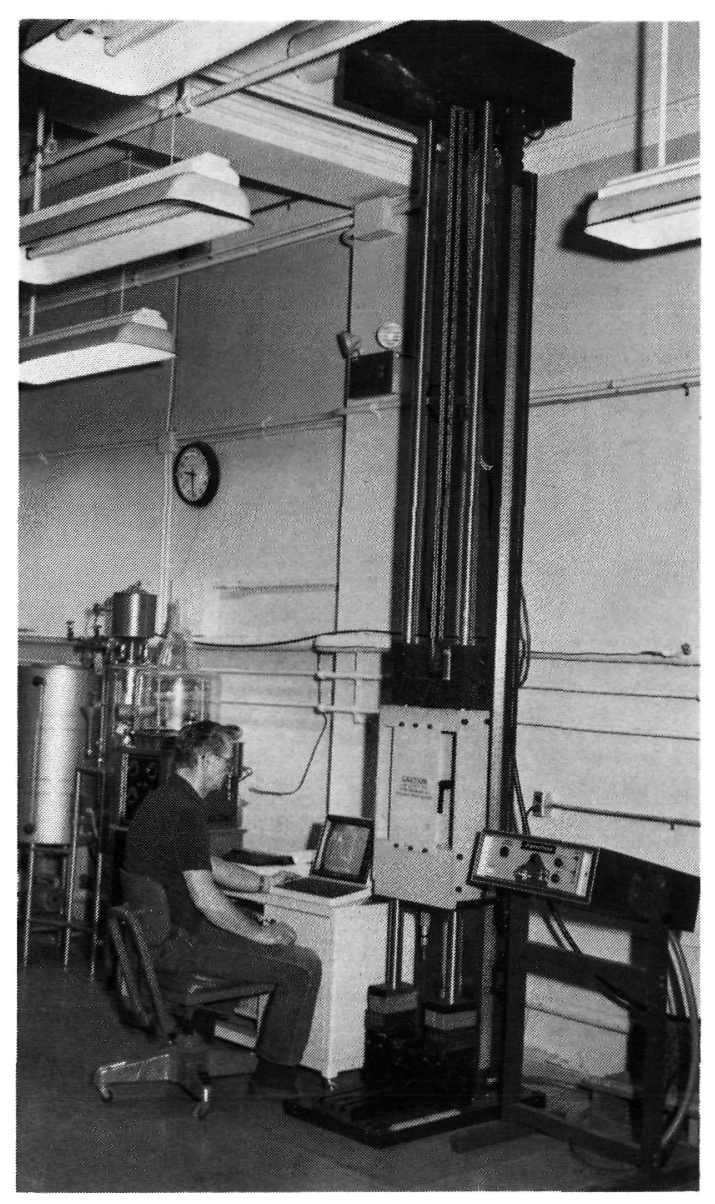

(a) Overall view.

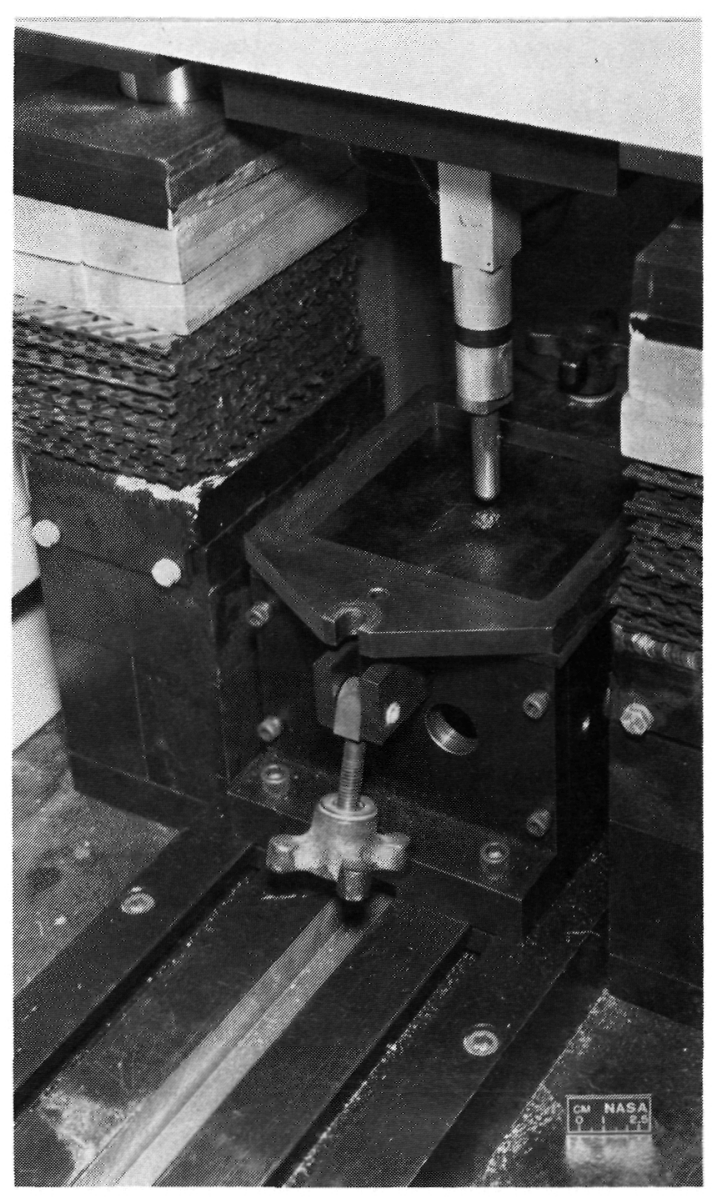

(b) Anvil and impactor.

Figure 1. - Instrumented drop-weight impact tester used to assess impact resistance of resins and composites. 


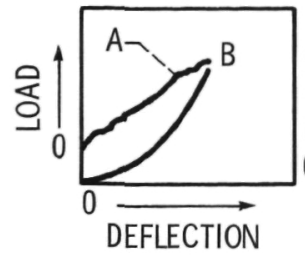

(a) 930.

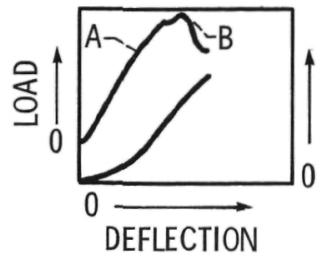

(c) 840 .

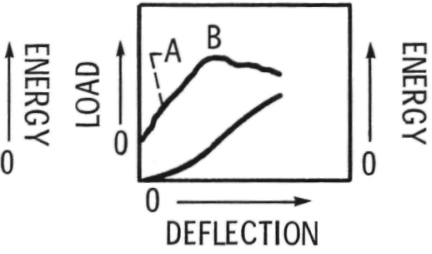

(d) $\mathrm{P}-1700$.

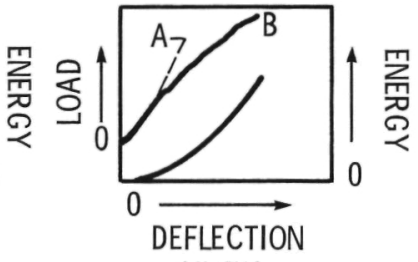

(d) 956 .

Figure 2. - Load-deflection and energy-deflection curves from impact tests of 30-ply crossplied composites. The lower curve is the energy curve. Point $A$ is the load at which damage initiates. Point $B$ is the maximum load.

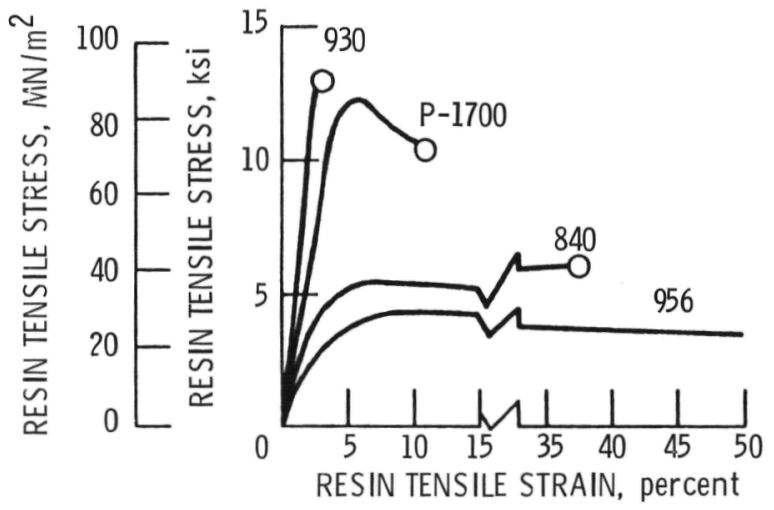

Figure 3. - Tensile stress-strain curves for the composite matrix polymers used in this study. 


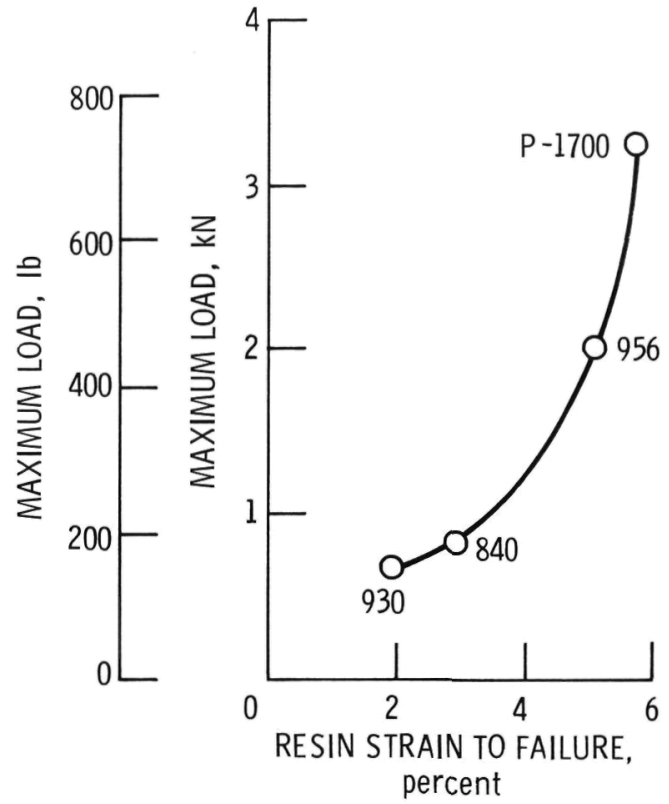

Figure 4. - Values of load at failure of the four matrix resins during impact and the yield or fracture strain for each of the resins.

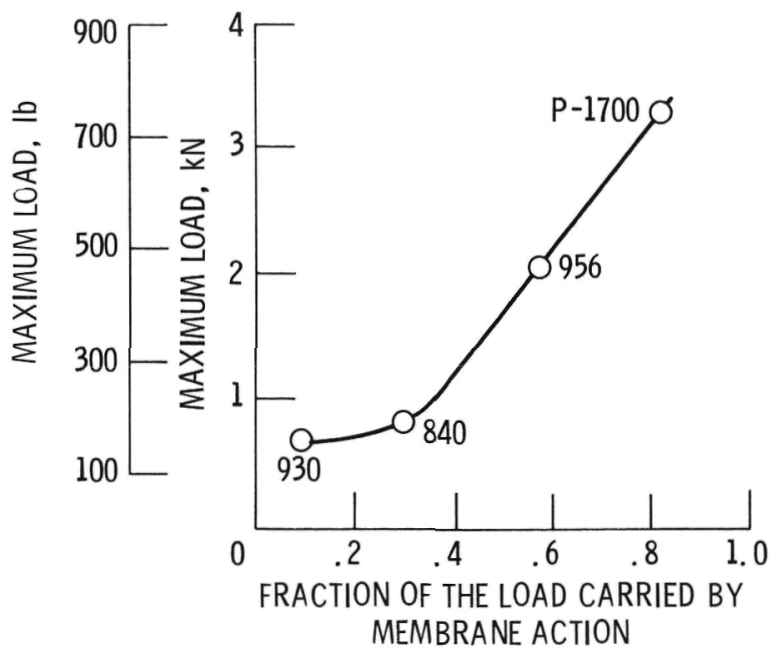

Figure 5. - The load at failure and the fraction of the load carried by membrane action for each of the four matrix resins used in this study. 


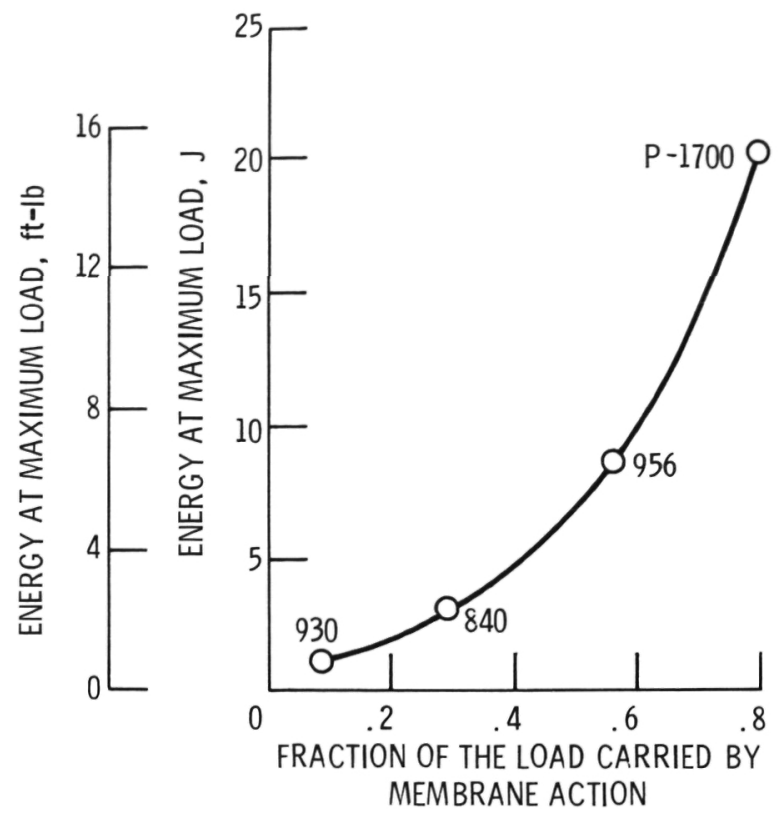

Figure 6. - The energy absorbed up to the time of failure and the fraction of the load carried by membrane action for each of the four resins used in this study.

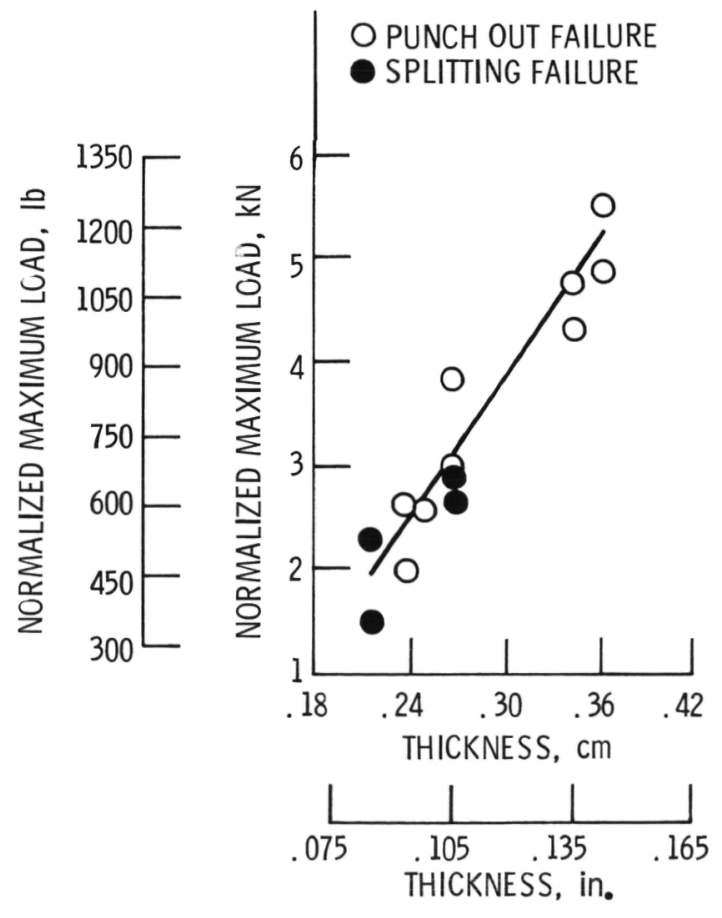

Figure 7. - Unidirectional composite maximum load, normalized to $60 \mathrm{vol} \%$ of fiber, for composite specimens of different thicknesses. 

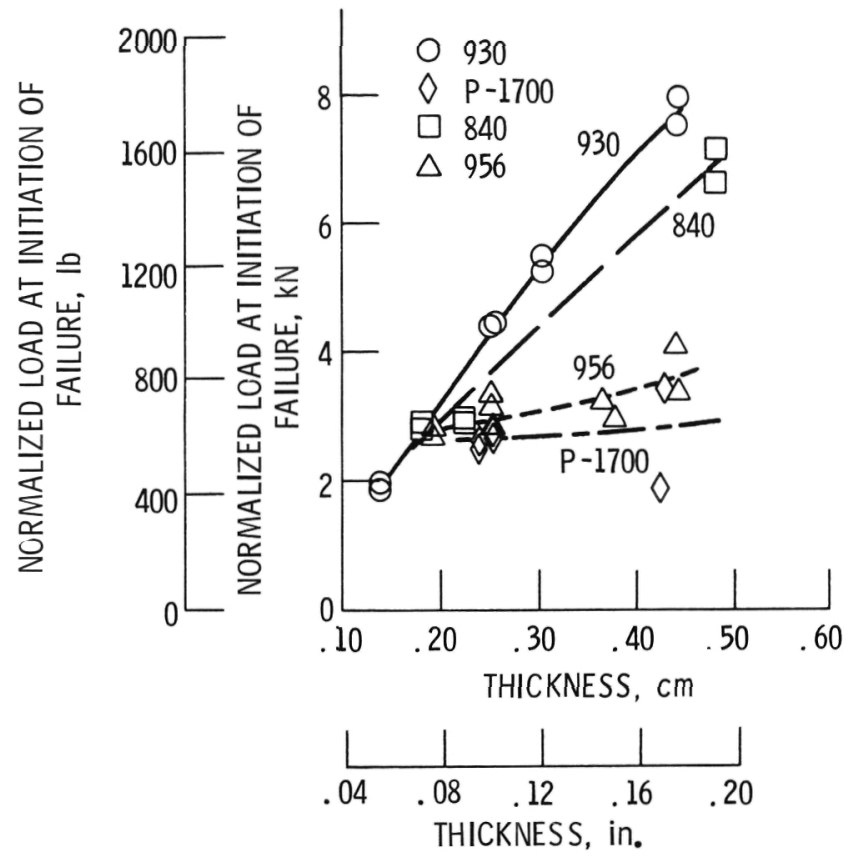

Figure 8. - Normalized loads at initiation of failure for crossplied composites of different thicknesses. Loads are normalized to $60 \mathrm{vol} \%$ of fiber.

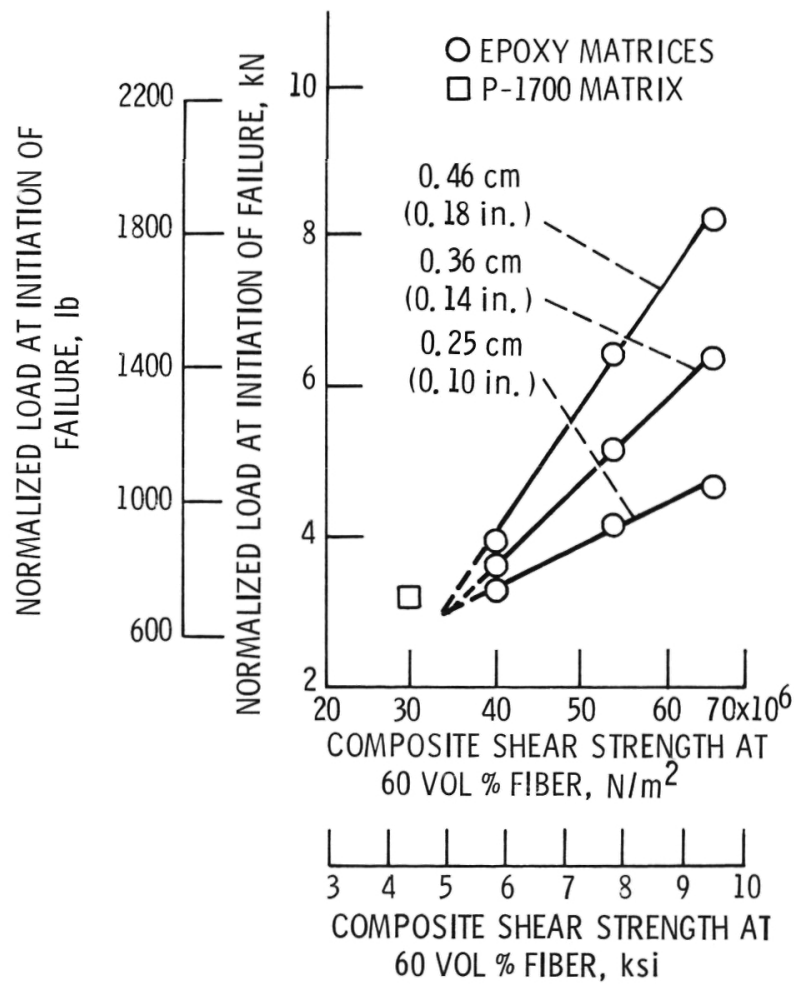

Figure 9. - Normalized loads at initiation of damage and composite shear strengths for the 30-ply crossplied composites. 


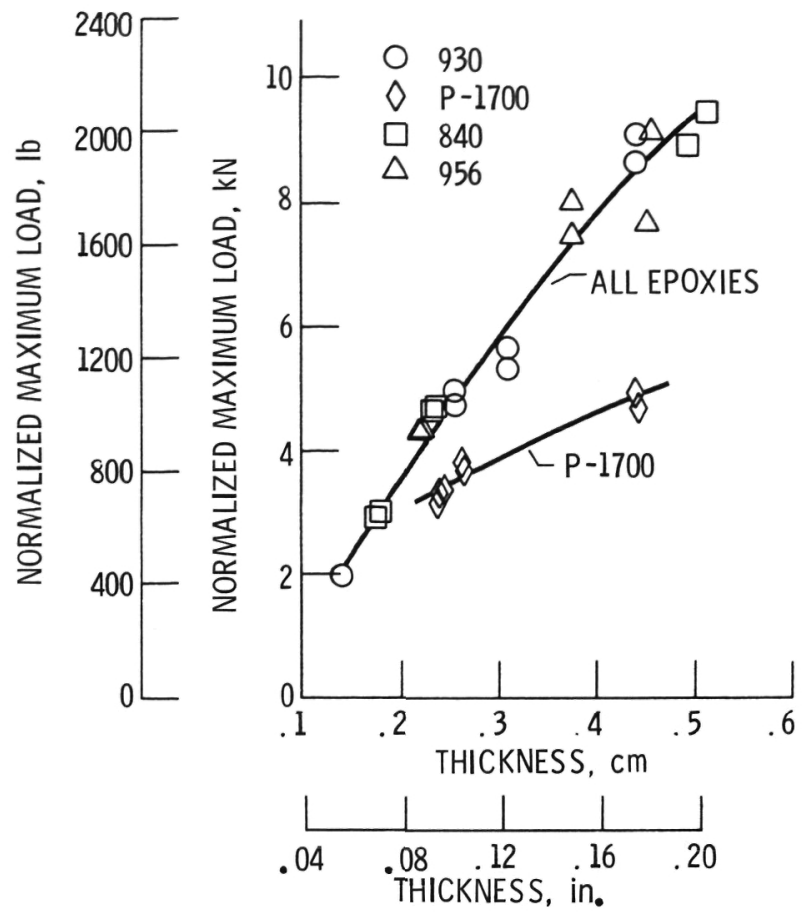

Figure 10. - Normalized maximum loads sustained by crossplied composites of different thicknesses. Loads are normalized to 60 vol \% of fiber.

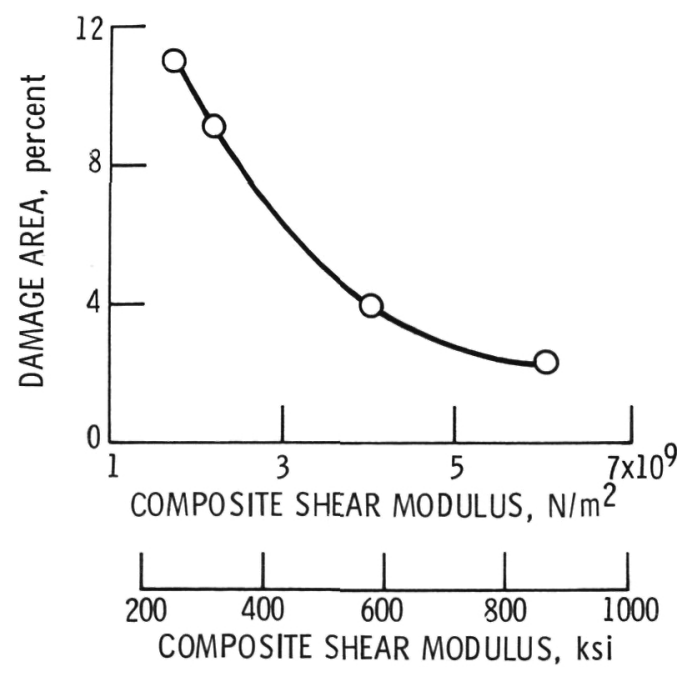

Figure 11. - Internal damage area of 30ply crossplied composites with different shear moduli. Damage area presented as percent of laminate surface area exposed to the impact. 


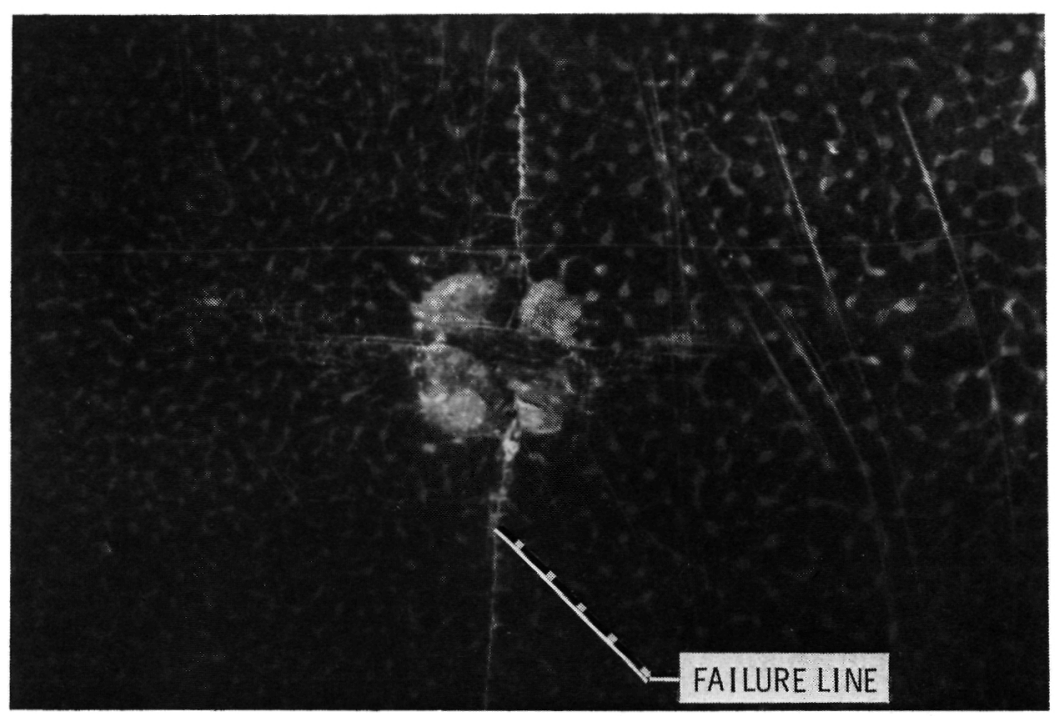

(a) Impacted surface, $x 2$.

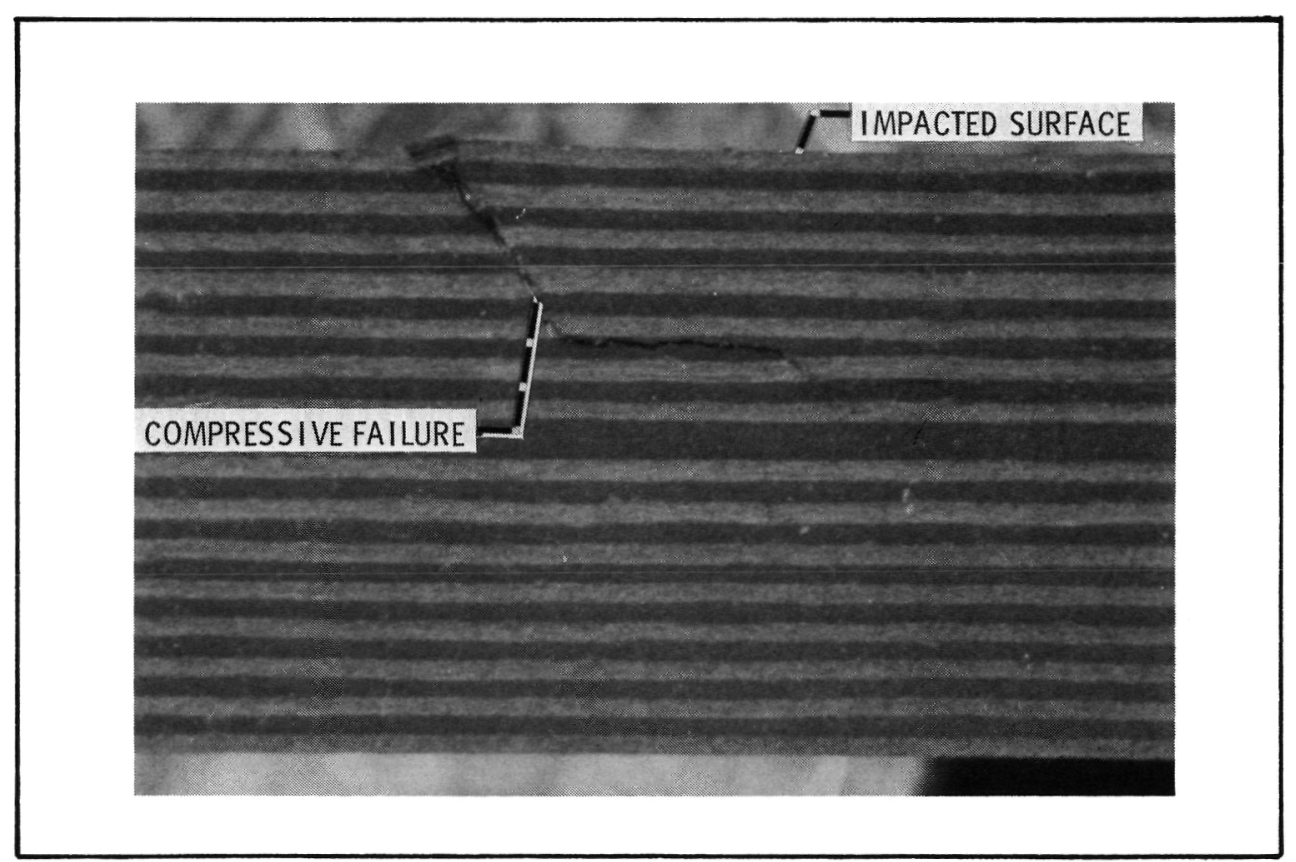

(b) Internal da mage away from the point of damage along the failure line, xl3.

Figure 12. - Thick, crossplied 840 composite after impact. I mpact velocity was $244 \mathrm{~cm} / \mathrm{sec}$ $(8 \mathrm{ft} / \mathrm{sec})$. Spherical-tipped impactor measures $1.27 \mathrm{~cm}(0.5 \mathrm{in}$. $)$ in diameter. 


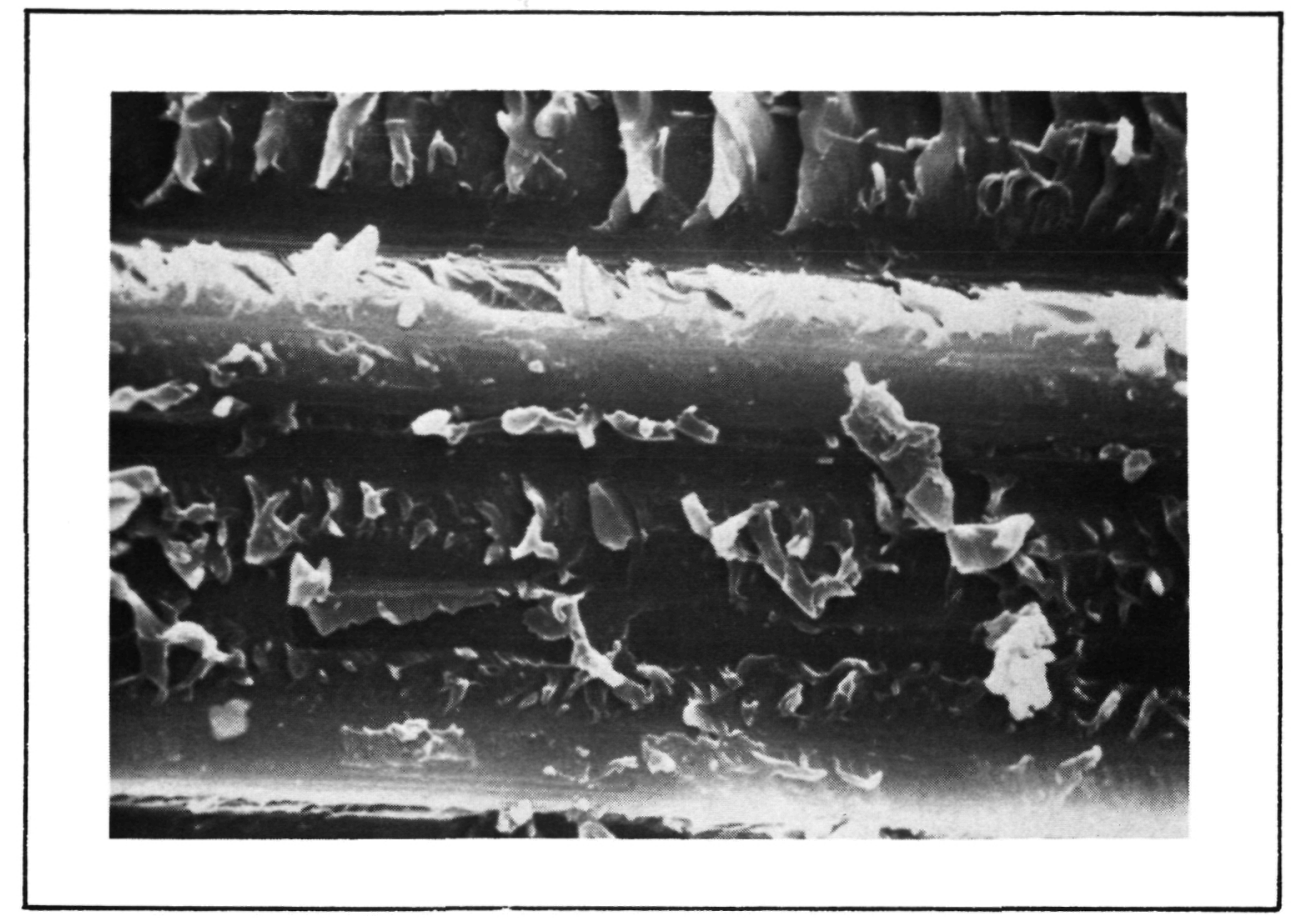

(a) Composite 930 magnified $5.9 \times 10^{3}$ times.

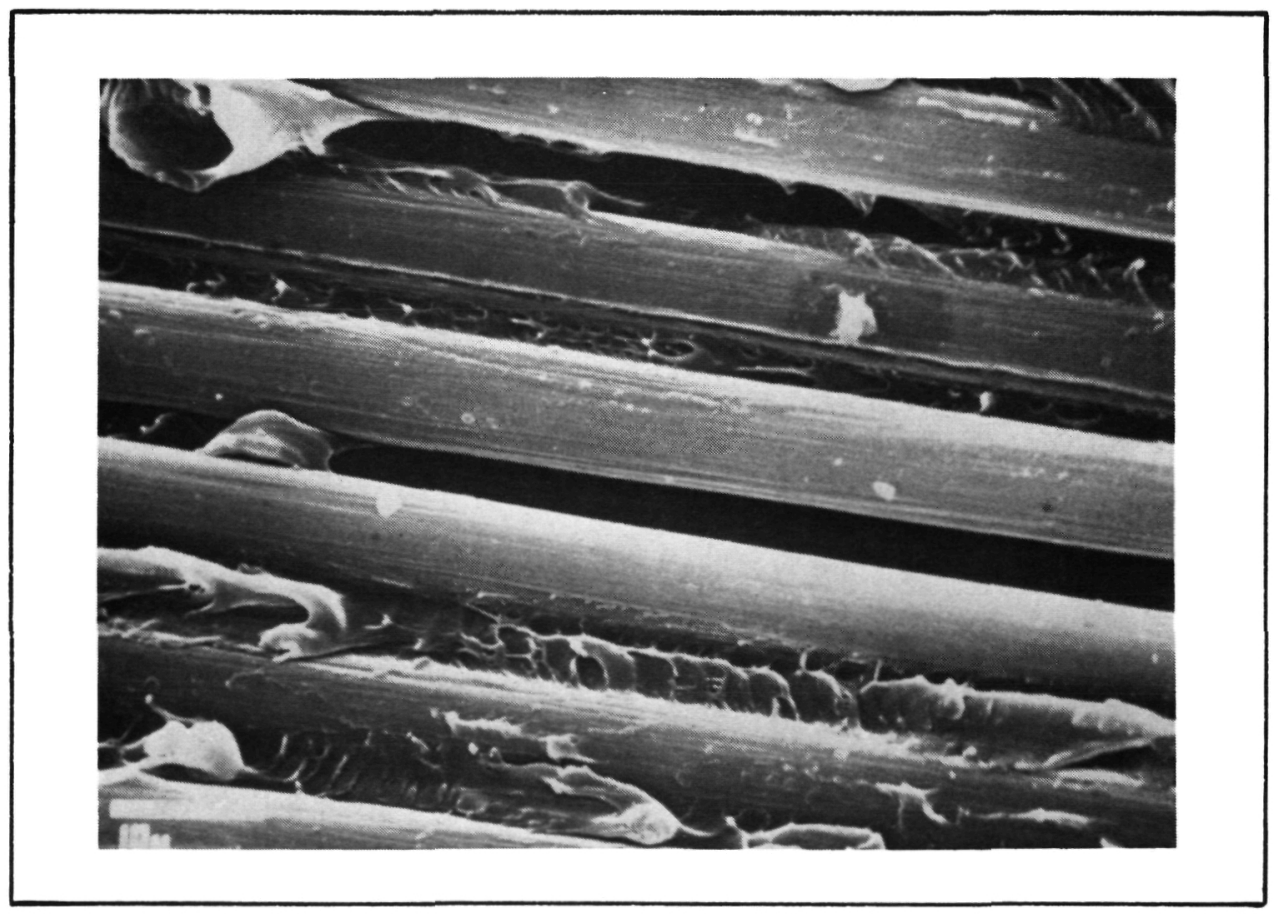

(b) Composite P-1700 magnified $1.8 \times 10^{3}$ times.

Figure 13. - SEM photographs of fracture surfaces of $10 \mathrm{deg}$ off-axis composite tensile specimens. Erose fiber surfaces and shear lips indicate a strong matrix-fiber bond and shear failure respectively, for the 930 composite. The smooth, clean fiber surfaces in $12(\mathrm{~b})$ indicate a very weak P-1700 fiber bond. 


\section{ORIGINAL PAG IS \\ OF. POOR QUALITY}

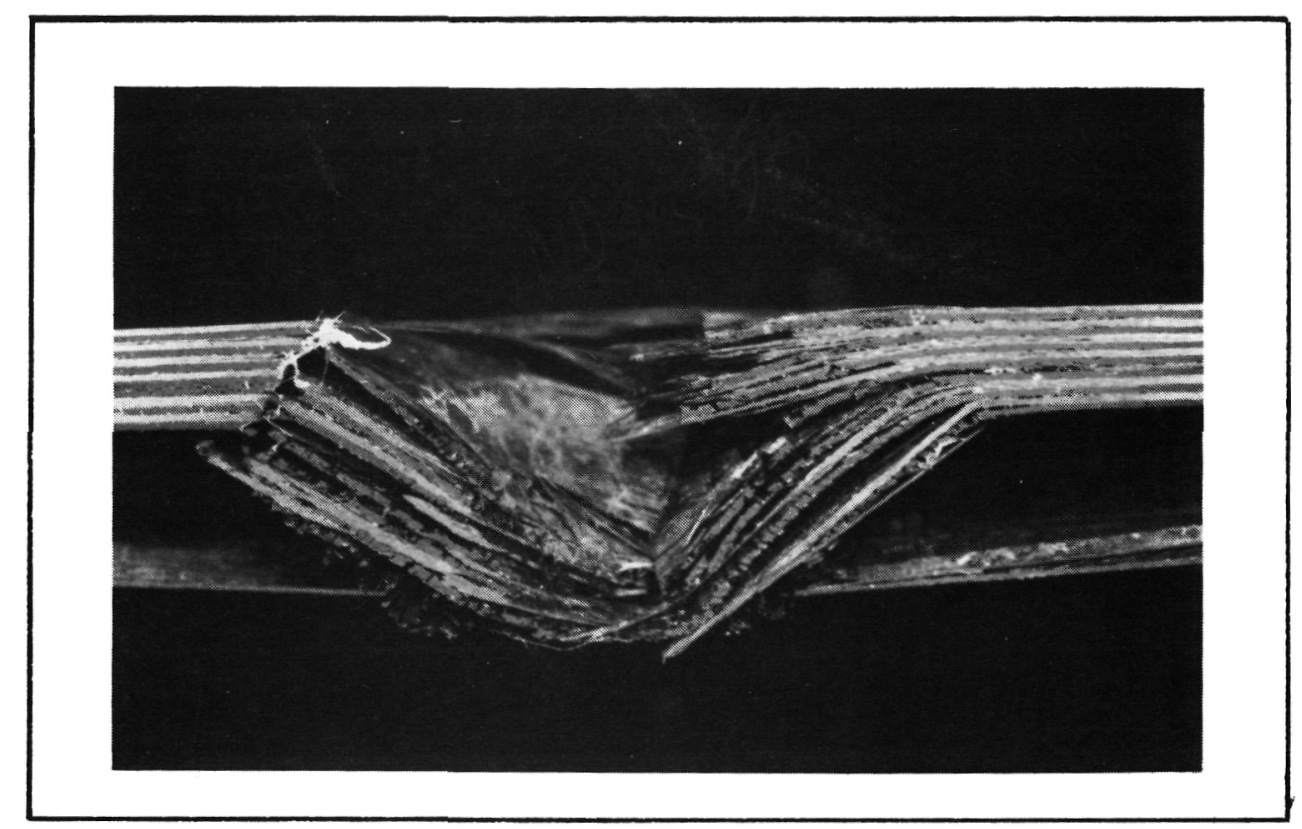

(a) Composite 930, x5.

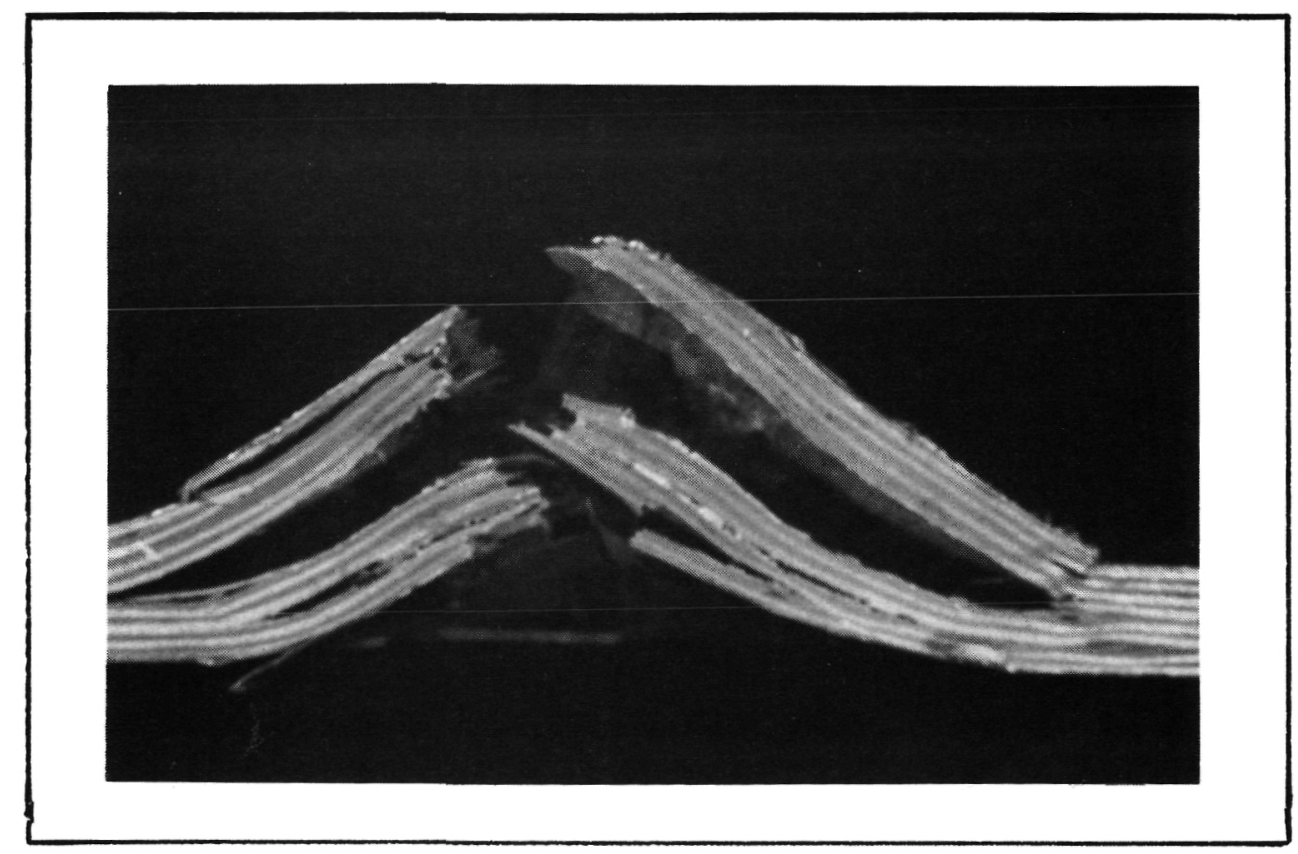

(b) Composite P-1700, $\times 5$.

Figure 14. - Cross sections of 15 -ply 930 and P-1700 crossplied composites after full penetration impact. Note the difference in the number of delamiations in the two specimens. 


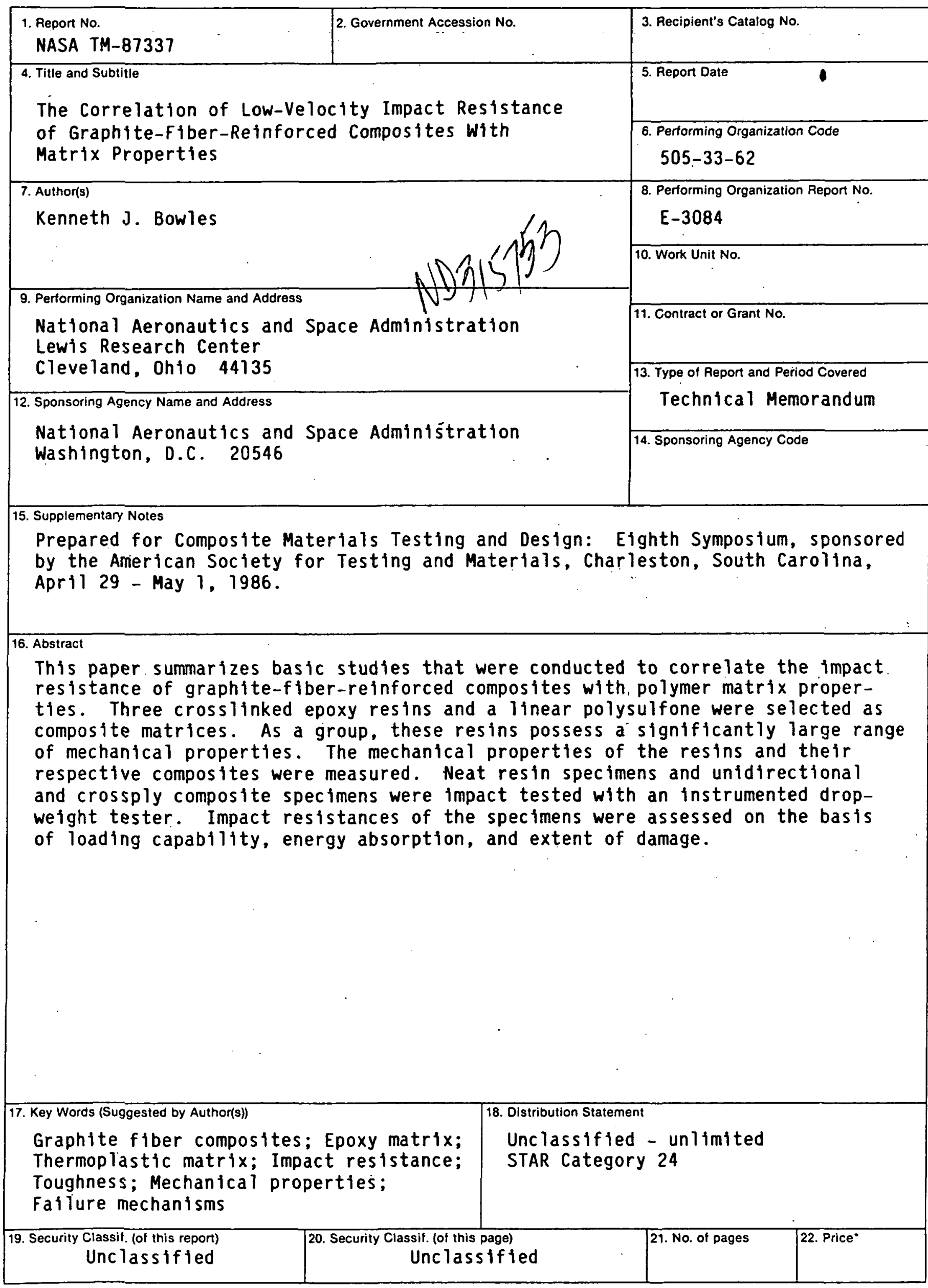

"For sale by the National Technical Information Service, Springfield, Virginia 22161 
National Aeronautics and

Space Administration

\section{Lewis Research Center}

Cleveland. Ohio 44135

Official Business

Penalty for Pitvate Uso $\$ \mathbf{3 0 0}$
SECOND CLASS MAIL

ADDRESS CORRECTION REQUESTED

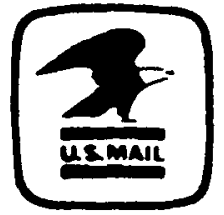

Postage and Fees Paid National Aeronautics and

Space Administration NASA-451 